\title{
Heterogeneity of demand and product innovation *
}

\author{
Thiago Caliari \\ Professor - Instituto Tecnológico da Aeronáutica (ITA) \\ Endereço: Praça Marechal Eduardo Gomes, 50 - V. das Acácias - São José dos Campos - São Paulo \\ CEP: 12228-900 - E-mail: thicaliari@yahoo.com.br
}

\author{
Ricardo Machado Ruiz \\ Professor - Cedeplar/UFMG - Universidade Federal de Minas Gerais (UFMG) \\ Endereço: Avenida Antônio Carlos, 6627 - sala 3032 - Pampulha - Belo Horizonte - Minas Gerais \\ CEP: 31270-901 - E-mail: rmruiz@cedeplar.ufmg.br
}

\section{Marco Valente}

Professor - University of L'Aquila,

Endereço: Via Giuseppe Mezzanotte, 67100 - L'Aquila - Italy

E-mail: marco.valente@univaq.it

Recebido: 13/01/2015. Aceite 21/07/2016.

\begin{abstract}
This paper discusses the relationship between heterogeneity of demand regarding choice procedures and product innovation. We propose an evolutionary model showing how consumers with imperfect information chose and select differentiated goods. The model shows the role of information and choice procedures and its relation with the innovative process. The price plays an important role, but the quality of information, error tolerance and criteria for preference ordering are important determinants of the performance of firms in an industry with product innovation.
\end{abstract}

\section{Keywords}

Demand. Information. Heterogeneity. Innovation. Evolutionary model.

\section{Resumo}

Este paper discute o relacionamento entre a heterogeneidade da demanda em relação a critérios de escolha e à inovaçao de produto. É proposto um modelo evolucionário que apresenta como consumidores com informação imperfeita escolhem e selecionam bens diferenciados. O modelo conecta a informação e os critérios de escolha e sua relação com o processo inovativo das empresas. Como resultados, pode-se verificar que o preço apresenta uma importante função, mas a qualidade da informação, os erros de tolerância dos agentes e critérios para ordenação de preferência são importantes determinantes do desempenho das firmas em uma indústria com inovação de produtos.

\section{Palavras-Chave}

Demanda. Informação. Heterogeneidade. Inovação. Modelo evolucionário.

\section{Classificação JEL}

C63, L22, D01.

- The authors would like to thank CNPq for financial support and the two anonymous reviewers for their helpful comments. All remaining errors are ours. 


\section{Introduction}

This paper presents a model that focuses on product innovation and how suppliers and consumers interact in the market place. Several models show how the determinants of the success or failure of firms are related to a firm's innovative strategies, but little consideration has been given to the role of consumers, specifically how they interact with suppliers and how they evaluate innovation in an environment with high informational asymmetries concerning product characteristics.

In most models, the focus is on the supply side as a simplification, usually justified by the assumption that innovation is driven by firms, not by consumers. However, the demand side plays an important role once consumers select products and use information to define the set of product substitutes. For example, in markets in which consumers have some technological capabilities and request information on product qualities, firms should seek innovations requested by consumers when selecting products, and the price differential may not be the most important variable, particularly when the innovation concerned are radically different from existing alternatives. More generally, we may assume that there is a whole set of minimal conditions that a consumer must respect just to take a potential offer into consideration, concerning not only the price but all the variables relevant to the consumer. When just one of these minimal requirement is violated the consumer will not be able to use the product, and therefore this will be removed from the option set irrespective from any further consideration.

This paper presents a model that shows how the heterogeneity of demand, information on product performance, and consumer choice processes can influence firms when they introduce a new product to the market. The model combines two others proposed by Valente $(2012,2014)$. In the first model, a modification of the NK model (KAUFFMAN, 1993), is used a landscape with distinct technological opportunities where firms hunt for innovations. The second model, based on the take-the-best (TTB) algorithm proposed to represent decision-making under uncertainty (GIGERENZER and GOLDSTEIN, 1996; GIGERENZER, 2000; GIGERENZER and SELTEN, 2000), is used to model consumers dealing with partial ignorance and trade-offs. The combination of these two models 
allows us to see the relevance of the process of choice in a market with frequent product innovation.

\section{Demand heterogeneity}

The analysis of firms' innovation focusing on the supply side dates from the original analysis of Schumpeter. In his theory of innovation, Schumpeter highlights the new products and new processes carried out within the firm and the entrepreneur's innovative spirit. It is a type of analysis that assigns a secondary role to those on the demand side, as already noted in the literature (METCALFE, 2001; NELSON and CONSOLI, 2010; NELSON, 2013). ${ }^{1}$

It is clear that firms have an important role in product innovation; however, it is not reasonable to assume that demand does not exert any influence on the level and direction of the innovative effort. Nelson (2013) points out that there are large differences between industrial sectors in how consumers respond to changes in the price and characteristics of goods. Existing products are modified all the time, even being reconstructed; new products are launched quickly; new processes reshape production. In short, it is necessary to consider demand and consumer choices in the context of "continuous streams of new opportunities and challenges with which consumers have to deal at any time" (NELSON, 2013: 35).

Each innovation allows consumers the possibility of changing their choice (basket of goods). It is also the case that such changes and choices influence how industrial sectors seek and select innovations. This causal linkage leads some researchers to classify the interaction between consumers and suppliers as a key element in the innovative process, for example in analyses that consider innovation systems (LUNDVALL, 1988). As pointed out by Nelson and Consoli (2010):

\footnotetext{
1 "Despite the obvious importance of consumer response to the changing and expanding range of goods and services they might buy in influencing this pattern of evolution, until recently evolutionary economists have not paid much attention to household behavior" (NELSON, 2013: 37).
} 
"Ignorance of alternatives aside, the evidence is clear that individuals do not have the kind of stable global preference orderings over different kinds and degrees of want satisfaction assumed by standard theory. Rather, preferences often are weakly established, under the influence of a variety of factors implicitly assumed away in standard theory, in particular strongly influenced by consumption experience, and hence path dependent, and potentially unstable. Under these conditions, it is not clear even how to define fully rational behavior" (NELSON and CONSOLI, 2010: 668). ${ }^{2}$

The instability in preferences stems from the cognitive limitations of consumers and from the process of the selection of suitable products, termed "satisficing" in Simon's pioneering arguments (SIMON, 1955, 1976, 1978, 1979). Even without considering rational limitations, Nelson $(1970,1974)$ highlights the importance of limiting the information available to consumers in market structures in relation to the technological characteristics and quality of the products. Furthermore, Stigler (1961) points out the relevance of information for price stability.

Olshavsky and Granbois (1979) also highlight the relevance of various intrinsic aspects of personal history as determinants of the purchase decision process. They note that patterns in decisions can be derived from cultural consumption settings or from standards and rules designed by groups of individuals - or by restricting them. Moreover, the choice can be made solely due to personal recommendations based on trust relationships (demand imitation). In some cases, choice involves perceptions in evaluating few alternatives or with little outside research and simple comparison criteria. ${ }^{3}$

2 Instability means that the consumers change their ordering preferences, but this will not be considered in this paper. The preferences will remain fixed, although there is imperfect perception due to myopic observation of markets from consumers. Future versions of the model should be worked to solve this limitation.

3 A set of works, mainly in the study of cognitive psychology, has highlighted the influence of these interactions and relationships on the rational choice pattern of agents. Among others, we suggest Tversky and Kahneman (1986), Thaler (1992), and Slovic (1990). 
Considering the relevance of these arguments for the understanding of consumer decisions, it seems clear that markets with a high level of innovation are complex and uncertain environments, which increases the cognitive limitations described above; i.e., they are environments analogous to those with high transaction costs (WILLIAMSON, 1989). Faced with the various alternatives, comparison using criteria based on knowledge of specific products in the market and the consequent ordering of their quality tends to fail. This problem results in information costs and the need to increase knowledge of these variables attests to problems in developing a hierarchy of products and services.

The difficulty of ordering preferences is argued in Valente (2012). Consumers generally have limited information on the technological details of all products because the costs of obtaining and processing information are high, or they have little motivation to invest time and attention on decisions that are of relatively low frequency and low importance in their lives. In other cases, the consumer primarily seeks products with specific characteristics and only considers other technological and economic dimensions secondarily, or seeks to minimize the price differential for example.

Saviotti (2001) is more emphatic in asserting the need for a more accurate and heterogenous account of demand in environments with strong technological innovation. The orthodox theory of demand highlights consumer behavior in considering a given relationship preference, a set of information and constant or stable supply. The question then is how to consider demand choice in an environment with persistent technological differentiation. As examples, we here present two cases: the mobile phone market and the pharmaceuticals market.

Although technological development in mobile telephony started in the mid-twentieth century (the first mobile phone prototype was patented in 1940 and the first commercial phone was developed by Ericsson in 1956), until recently, specifically in the early 1980s, this technology was not used for commercial purposes on a profitable scale. In 1989, four million people around the world used mobile phones. In 2014, the number of active cell phones will reach 7.3 billion. This means that if the predictions were correct, there will now be more use cell phones in use than there are people on the planet. 
Of the known areas of technological diffusion, this is the one with the largest percentage of adoption: according to data from the International Telecommunication Union (ITU), over a period of approximately 25 years (1989-2013), the average consumption per capita of mobile phones around the world went from practically zero to one mobile phone. These data only relate to phone lines. The acquisition of the mobile phone shows even more peculiarities. Analyzing its dynamics, a drastic reduction in the product life cycle can be observed as well as internal technological revolutions caused by the launch of new products. Furthermore, the inclusion of new features and applications within a single device (e.g., high definition camera lenses, video recording, games) has led to the inclusion of these products in different markets.

In essence, this observation illustrates how difficult it is to analyse the choice of goods. If about eight years ago it was impossible to find a smartphone, how does one sort and classify the preference of consumers in this market now? Moreover, how does one consider the gradual change in choice preferences over, let us say, one year regarding the variety of products? In addition, due to the complexity of software in these devices and the quantity of functions, how can we sort them in an increasing order of quality? How is it possible to combine these multiple features within a given budget constraint?

It seems clear that in such an environment there are complications for consumers in terms of choice. Forecast errors in the evaluation of alternatives and different levels of tolerance in the product quality ratings are thus frequently found in this type of market. Limited information, environment complexity, and time constraints affect the process of choice and therefore the performance of products on the market.

The pharmaceutical market is another interesting example of the relevance of heterogeneity of demand, particularly with regulatory changes establishing new comsumption patterns. Despite its longer sectoral history than the example of mobile telephony, the pharmaceutical industry is highly dependent on the level of investment in research and development (R\&D), marketing, sales promotion and technical assistance to maintain the market power of incumbent firms in the market. In this market, the products combine considerations of price, availability, information on side effects or the 
inclusion of new active ingredients with distinct collateral effects, and the efficacy of different products in treating the same disease. Overall, it is frequently possible to observe several drugs within the same therapeutic category but with different technical specifications being used to treat the same disease.

So, how are products chosen in an industrial sector with specific technology that is little known to the general population? How does one classify the quality of products across so many different and sometimes unknown characteristics? These questions are not restricted to individual consumers. Firms also have difficulties in choosing technologies, patents to be licensed, capital goods, and even inputs. There is a wide range of industries in which forecast errors in the evaluation and issues with tolerance levels are frequently found in the classification of products. ${ }^{4}$

Some studies highlight this process of choice focusing on consumers' bounded rationality in innovative markets. Aversi et al. (1999) developed a demand model that has very similar results to the empirical evidence. Windrum and Birchenhall (1998) discuss the concept from the perspective of product life-cycle theory, i.e., delegating the dynamics of technological change specifically to changes in technologies. According to these authors, it is necessary to analyze technological innovation considering both consumers and suppliers.

Malerba et al. (2007) point to the relevance of the varieties of individual consumers' preference for the survival of firms at the front of market innovations. Windrum et al. (2009) examined the influence of the distribution of consumer preferences in relation to technological standards and other quality patterns of adopted products. Valente (2012) offers a theoretical model for treating the cognitive skills of consumers across different product characteristics.

In short, the interdependence between demand and product innovation cannot be neglected, so it is necessary to take into account consumers' choice and demand heterogeneity in environments with recurrent innovations. In the following sections, we address specific treatments suggested for the technological innovation of firms and

${ }^{4}$ It is worth recalling that the usual way of influencing demand in pharmaceutical industry is through physician-oriented marketing. There is sense behind this strategy as the physician has more knowledge regarding technical characteristics than the patient, so it is based on an established relationship of trust. 
consumer demand aimed at capturing the results in the market for heterogeneous consumer preferences.

\section{Technological innovation: the NK-like model}

Valente (2014) propose a model called NK-like, derived from Kauffman's (1993) NK model, which aims to incorporate modifications to resolve the limitations in using the NK model in the social sciences, especially in examining technological innovations under the condition of the multiple determinants of innovation and uncertainty concerning the results.

The NK model was developed in the field of biological sciences by Kauffman (1993) and shows the effects of the biological fitness of agents (the fitness value) in genetic mutations. Despite being a model that seeks to explain complex environments, it has proved successful in analysis because it is an easy tool that generates a representation of a problem that can be modified to make it simple or complicated, depending on the parameterization required for each case. As pointed out by Valente (2014), NK-inspired models are becoming popular among simulation modelers in economics and management, since it allows explore the problem space on the base of local and myopic information. This is a great useful tool when considering complex systems. ${ }^{5}$

The NK-like model is proposed as a replication strategy of the useful properties of the NK model incorporating advances that seek to address some of its limitations. Specifically, the model has the following modifications:

1. Multidimensional real-valued landscape: The landscape of the NK-like model is represented by real values, composed of $\vec{x}=\left\{x_{1}, x_{2}, \ldots, x_{n}\right\} \in \mathfrak{R}^{N}$, in which the fitness value is represented by a real value $f(\vec{x})$. Still, the values for the function domain and subdomain can be determined freely by the researcher.

5 Considering this and the ease of implementation, we opted for the use of NK-like model in the paper despite all other possible strategies to consider innovation. As it is an initial model for a more extensive research agenda, this estrategy is useful since we establish a powerful model for innovative complexity since now. 
2. User-determined maximum and overall shape of the landscape: Unlike the NK model, in which the location of the maximum and the landscape style were determined randomly, in the NKlike model, the global maximum is set by the modeler. ${ }^{6}$ The landscape format is defined by a well-behaved function, so that the modeler can separately measure any point on the landscape, determining peaks in the overall range of maximum likelihood, amongst other attributes.

3. User-determined interdependence: For any given couple of dimensions, $i$ and $j$, the user can set a varying degree of interdependence, $a i, j$, ranging from full independence to maximum interdependence. Intermediate and varied levels of interdependence allow us, for example, to define landscapes where a dimension depends strongly on some dimensions and weakly on others.

The NK-like model presents a fitness function defined for $\mathrm{N}$ entry variables (dimensions) and a search algorithm (fitness function) generating results for each dimension point (fitness value). The fitness value of a point in the landscape is the average of the fitness contribution for each of $\mathrm{N}$ dimensions (entry variables):

$$
f(\vec{x})=\frac{\sum_{i=1}^{N} \phi_{i}(\vec{x})}{N}
$$

where $\phi_{i}(\vec{x})$ is the contribution to the fitness of each dimension $i$. In the NK-like model, this is a deterministic function defined as:

$$
\phi_{i}(\vec{x})=\frac{\operatorname{Max}}{\left(1+\left|x_{i}-\mu_{i}(\vec{x})\right|\right)}
$$

where Max is a pre-determined parameter defined by the modeler for the maximum of the function. Thus, $\phi_{i}$ is a decrescent function of the distance among the variable values $\left(x_{i}\right)$ and a function $\mu_{i}(\vec{x})$, defined as:

$$
\mu_{i}(\vec{x})=c_{i}+\sum_{j=1}^{N} a_{i, j} x_{j}
$$

\footnotetext{
${ }^{6}$ Global maximum is achieved when $f\left(\vec{x}^{*}\right) \geq f(\vec{x}), \forall \vec{x}$.
} 
The value $\mu_{i}$ defines a goal that determines the greater level of contribution of a dimension (entry variable) for the overall fitness function when it is equal to $x_{i}{ }^{7}$.

The above function is flexible to allow the incorporation of particularities described in the NK-like model, precisely those that are not obtained in the NK model. It is possible to define: (i) the maximum value of the function, (ii) the global optimum point, ${ }^{8}$ and (iii) the interdependencies between the dimensions $i$ and $j$, varying only the $\alpha_{i, j}$ value.

The search algorithm follows the same definition as the traditional NK model by means of unilateral changes (one-bit mutation). The strategy consists of the following steps:

1. Choose a random direction (in which the gene variation is made).

2. Define the value of $\Delta_{\mathrm{T}}$ mutation in the selected dimension.

3. If the fitness value increases, move to the new product technology.

4. If the fitness value decreases, continue with the same product technology.

The $\Delta_{\mathrm{T}}$ value in this model is analyzed as a constant parameter represented by a small amount $\left(\Delta_{\mathrm{T}}=1\right)$. The $N$ input variables must be understood, as the resources (infrastructure, human resources, etc.) needed for the development of a new product that has been technologically improved. The fitness value, then, is the result of the combination of the input variables.

Each of the $\mathrm{N}$ resources makes a contribution $\left(\phi_{i}(\vec{x})\right)$ to the "quality" of the product, which is maximum at a certain point, expressing the possibility of the exhaustion of the technological frontier. The interdependence $\alpha_{i, j}$ expresses the technological complexity of the modeling exercise by setting the difficulty to achieve the overall maximum fitness value: the greater the interdependence, the greater the possibility of achieving technological lock-in (VALENTE, 2014).

\footnotetext{
7 More results from this proposed specification are presented in Valente (2014).

8 The global optimum is defined at the point $\vec{x}^{*}: c_{i}=x_{i}^{*}-\sum_{j \neq i} a_{i, j} x_{j}^{*}$.
} 


\section{Demand: the take-the-best (TTB) model}

The take-the-best (TTB) model has been developed to capture consumers' diversity in choice procedures to explain market results when introducing new products. The idea is to present a model that incorporates a decision-making algorithm based on bounded rationality, i.e., a process of selection and ranking of products with complex and/or uncertain characteristics or information; this is a different decision procedure compared to the orthodox "optimal or perfect condition" model. ${ }^{9}$

The TTB model assumes that consumers have the task of making purchase choices observing a range of alternative products/services with different characteristics, represented by a vector of features. Consumers make their decisions based on the comparison of available products with respect to a single or dominant feature: a partial and hierarchical evaluation. Thus, the algorithm only requires that the best-or better- product be identified for each dimension, considering one to be dominant or higher.

The first step in the choice involves observing differences in personal competence to distinguish relevant characteristics for the selection and ranking. The choice is made based on the probability of each product being judged the best with respect to a given feature. It is considered that consumers do not directly observe the actual values $v_{k}^{X}$ of the individual characteristics (consumer $k$ and product $X)$, but rather the following expression:

$$
\hat{v}_{k}^{X}=\operatorname{Norm}\left(v_{k}^{X}, \Delta\right)
$$

where $\operatorname{Norm}(\mu, \sigma)$ is a uniformly distributed random function, and $\Delta$ the variance of the random variable, working as a proxy variable for perception errors arising from ignorance about the quality of the product. The lower the values of $\Delta$, the more accurate the product information derived by the consumer; the opposite holds for higher values of $\Delta$.

9 References to the market as described by Akerlof (1970) are certainly appropriate. In such a market, there is asymmetric information, not explicit, and opportunistic behavior, etc. However, in Akerlof's market, the product was in use, whereas in the specific market proposed for study here, the product is new. Thus, the same doubts apply to the consumer. 
In addition, there is a second step taken in choice related to consumer tolerance regarding different products. The implementation of the model includes a parameter representing consumer tolerance for differences in product characteristics. Comparing two products $\mathrm{X}$ and $\mathrm{Y}$, the model assumes that they are equivalent if:

$$
\hat{v}^{X} \approx \hat{v}^{Y} \Leftrightarrow \frac{\left|\hat{v}^{X}-\hat{v}^{Y}\right|}{\max \left(\hat{v}^{X}, \hat{v}^{Y}\right)}<\tau
$$

where $\tau$ is a coefficient between 0 and 1 . When $\tau=0$, any difference in that feature is understood by the consumer as certifying the superiority of a product; in contrast, high $\tau$ values indicate that even large differences are considered irrelevant in consumer choice, taking products to be equal regarding that feature.

A consumer can discard a product either because it is not affordable (or judged as wanting in some respect other than price), or because a competing product appears to be more attractive. Although the eventual result is identical (the consumer not buying the product), we need to distinguish between the two cases to assess properly the economic conditions of the market. For example, in the second case, the removal of a competitor product may lead the consumer to choose the product, but that will not happen in the first case.

There are minimum requirements for the consumption of each product, i.e., for the products to be regarded as viable for purchase. Formally, the model assumes that each $k$ consumer has a vector of minimum requirements $\vec{m}_{k}=\left\{m_{k}^{1}, m_{k}^{2}, \ldots, m_{k}^{m}\right\}$ for each feature of the product. A product $X$ viable for consumption is one in which $v_{k}^{m}>m_{k}^{m}$ for all $m$.

Thus, the decision mechanism of choice is based on the take-the -best (TTB) strategy, in which the choice of an item is made based on a number of possible alternatives defined in a multidimensional space. The proposition of the TTB strategy is an example of bounded rationality. We claim that this selection process begins by noting the difficulties in undertaking complete and costly market research, which would involve time and resources to make the optimal choice. In these circumstances, the choice is made to define the best product for a specific characteristic or set of characteristics classified as important by the consumer. Such behavior is a bounded rationality 
choice, in which decision makers use the superiority of the product in relation to this specific characteristic (or set of characteristics), which itself is hierarchically significant, to justify their decision.

The algorithmic procedure used is the cyclic repetition of the following steps until the third step is satisfied in a clear process of satisficing in Simon's (1978) terminology:

1. Consider initially all potential options to choose from.

2. Choose a characteristic between the $m$ available features, i.e., the most important characteristic for that consumer (hierarchically superior characteristic).

3. If a product has score higher than others with respect to this characteristic, considering forecast errors and tolerance level, the choice is made;

4. If option 3 is not satisfied and more than one option has similar values with respect to the feature selected in step 2 , remove options with lower values and restart the process from step 2.

This procedure is as simple as possible, but other features can be added in the selection. For example, the selection can incorporate two or three hierarchical characteristics in different ways, ultimately forming distinct product sets. For complex products (multiple and complex characteristics), this procedure generates differentiated decisions of consumption, which is a consequence of the information distributed by the seller on the market, and how it is received and organized by the consumer.

It is worth noting that this process of choice fits with the different types of strategies that classify firms as leaders on some dimension, for example, lowest price, highest quality, best technology, or regular supply. Depending on the consumer's preferences and the information provided and processed, one or another group of goods will be selected for consumption, and thus we will have distinct product groups with different cross-elasticities of demand. ${ }^{10}$

\footnotetext{
${ }^{10}$ As theoretical references, we highlight Caves and Porter (1977) and Porter $(1979,1980)$, which address the segmentation of intra-industry competition and business strategies typology. We currently have an infinite variety of "types and types of strategies," but all of them try to differentiate products and services by highlighting a superior feature that will guide a firm's decisions and the need to bring this information to the consumer.
} 


\section{Basic model}

To link the two models presented above, some simplifications have to be made. First, we consider just a single market in which 10 firms offer products. Each firm offers just one product, and thus there are always 10 products on the market. Each product $p$ has two characteristics, $\left(Y_{p}=\left[y_{p}^{1}, y_{p}^{2}\right]\right)$, where $y_{p}^{1}$ is the price and $y_{p}^{2}$ is a technological characteristic. ${ }^{11}$ There is a positive relation between the technological feature and the predisposition of consumer to choose that product, and a negative relation between the price and the chance (or predisposition) of the consumer to buy it. Fig. 1 presents an overview of the model.

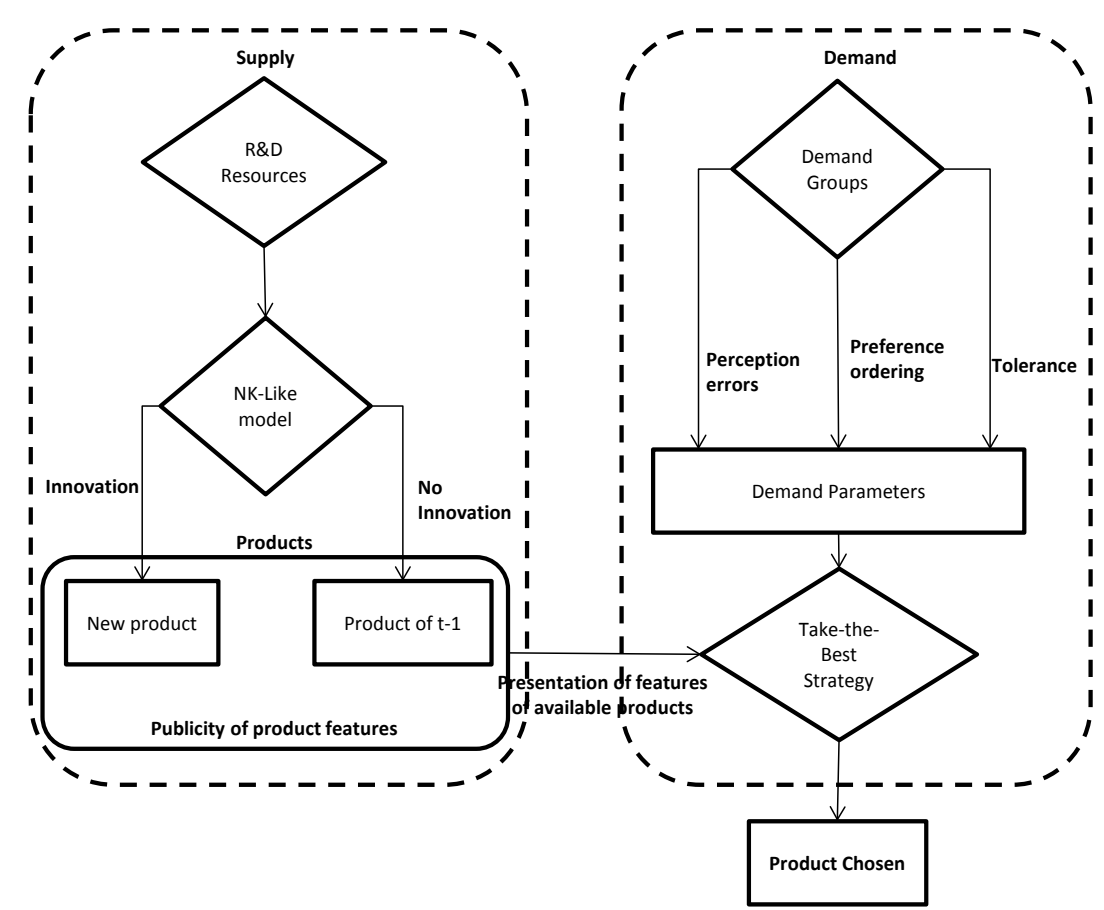

Fig. 1 Flowchart of the model

Source: Own elaboration.

All products are able to the consumers and the interaction consumer-firm is mediated by the market at a microeconomic level - there is no particular negotiation. Firms present on the market

${ }^{11}$ One might think, for example, of the information storage capacity in the information technology markets, or the number of security devices in the automotive market, amongst others. 
product features regarding price and technology and each consumer of a group observe these features and get a choice regarding their demand preferences. These micro interactions will define macro patterns, as will be explored after as stylized patterns of competition.

\subsection{Innovation and technology}

Initially, there is a resource for $\mathrm{R} \& \mathrm{D}$ investment that will define the capacity of firms to undertake technological searching. We decided to establish a simple rule of investment for innovation for each company: R\&D takes time and only rarely results in innovation. Thus, for each firm, we establish a random variable with a positive value in a sample space $\Omega=\{0,1, \ldots, 100\}$. At each time point, its value is decreased by one unit; when this value reaches zero, an innovation is achieved by the firm. This strategy follows the search process defined by the NK-like model as already specified above. After each attempt at innovation, a new random value for this variable is calculated for the firm (in the same sample space), and the process goes on as before. If a firm develops an innovation, it offers a new product; if the firm does not innovate, it offers the same product as in period $t-1$. This environment will define the characteristics of the products, mainly the technological attributes and price.

The NK-like model acts on the technological feature, $y_{2}^{i}$, scanning the solution space in search of improvements to the attribute (local and myopic search, as already explained). The landscape follows the minimum number of variables $(\mathrm{N}=2)$ each one with 200 dimensions - global optimum set at $(100,100)$ - so that the impacts become clear, ${ }^{12}$ yet establishing complete interdependence between the dimensions $\left(\alpha_{i, j}=1\right) .{ }^{13}$ The landscape has a single global maximum value $(\operatorname{Max}=1)$.

${ }^{12}$ It is followed the proposition made in Valente (2014) regarding the minimum number of variables $N$ as a way to replicate the effects of a complex system in the most simple way (Keep it simple, stupid! strategy). Still, a global optimum set defined as $(100,100)$ with symmetric landscape means that each variable $N$ has 200 dimensions. So, the mutation $\Delta_{\mathrm{T}}=1$ at each innovative attempt is made on 200 dimensions.

${ }^{13}$ The aim of establishing the maximum level of interdependence is to evaluate the relationship between demand and innovation in complex technological environments because, as stated earlier, interdependence is directly related to the emergence of local maxima and possible technological lock-in. 
The fitness function follows the initial presentation (section 3) and all initial values of the characteristic $y_{p}^{2}$ are considered equal to 0.05 , at a considerable distance from the global maximum $(\operatorname{Max}=1)$. This ensures that companies do not differ in terms of technology at the beginning of the simulation. The values of the characteristic $y_{p}^{1}$ (price) are presented later.

\subsection{Demand and consumers}

The consumers have defined parameters for perception errors, tolerance levels, and order preferences. Using this information, they verify the products offered and choose one for consumption based on the TTB strategy.

There are two distinct consumer groups, each one with a different specification in relation to the preference for product characteristics. Group 1 has a preference regarding price $\left(v^{1}\right)$ and Group 2 has a preference regarding the technological atribute $\left(v^{2}\right)$. The purpose of this strategy is to demonstrate how different patterns of selection affect the market and technological outcomes of firms.

Each group has 100 consumers. It is assumed that all consumers have sufficient income to purchase the products offered and they make only a one-time purchase in the simulation period. The maximum amount of money spent by the consumer for each product is $\$ 15$ (i.e., the maximum value accepted for the feature $v^{1}$ ). We consider $\Delta=1$ and $\tau=1$ for the first simulation, which means that consumers have an entirely imperfect perception of the products' characteristics and they are quite tolerant in their comparison between the goods. In addition, the minimum requirements for consumption are lower than those for products $\left(m_{k}^{X}>y^{X}\right)$ as a means of allowing all products to be available to the consumer at the beginning of the simulation. The minimum value for the characteristic $v^{2}$ is zero.

\subsection{Price determinants}

The firms follow a simple rule for price, based on market share variation. However, a firm only changes its price if the following condition is met: 


$$
m s_{f, t}-m s_{f, t-1}>\alpha
$$

where $\alpha$ is a value determined exogenously and $m s_{t, f}$ is the market share of firm $f$ in period $t$. For the simulations, we decided that there is a variation in price for a variation in demand above $1 \%(\alpha=0.01)$. Fundamentally, if the above inequality occurs, the pricing rule is as follows:

$$
p_{f, t}=p_{f, t-1 \cdot} \cdot\left[1+s c .\left(\operatorname{sign}_{f}\right)\right]
$$

where in exogenous $s c$ is a constant that defines the magnitude of the price change by firm $f$ (for the following simulations, this was defined as $s c=0.02$ ). The variable sign is the direction of the price change, defined by the following equation:

$$
\operatorname{sign}_{f, t}=\frac{\left|d_{f, t}-d_{f, t-1}\right|}{d_{f, t}-d_{f, t-1}}
$$

where $d_{f, t}$ is the demand of firm $f$ in period $t$. If $d_{t}>d_{t-1}$, then the variable displays the value $\operatorname{sig} n=1$, and the product price variation offered by firm $f$ will be positive. Minimum values were introduced to set price and demand by companies in the form below:

$$
\begin{aligned}
& p_{f, t}=p_{f, t-1} \cdot(1-s c) \text { if } d_{f, t}<\min D, \text { and } \\
& p_{f, t}=\min P \text { if } p_{f, t}<\min P
\end{aligned}
$$

for which $\min D$ is the minimum level of demand required by the firm and $\min P$ is the minimum price charged, defined as 0.01 and 1.00 , respectively. The minimum price should be understood as the perfectly competitive price - the marginal cost - considered constant. The initial price of all products of all firms is $\$ 4$.

\subsection{Market share and firm demand}

The participation of firm $f$ in the market is defined by:

$$
m s_{f, t}=\frac{d_{f, t}}{\sum_{s=1}^{N_{s}} d_{s, t}}
$$


where $d_{f, t}$ is the quantity demanded from firm $f$ in period $t$ and $\sum_{s=1}^{N_{s}} d_{s, t}$ is the sum of the sales of all firms. Note that each firm will offer one product to the market. Thus, the market share of the firm is similar to the market share of the product offered by the firm.

\subsection{Profits, costs and stocks}

The profit of firm $f$ in period $t\left(\pi_{f, t}\right)$ is given by:

$$
\pi_{f, t}=p_{f, t} \cdot d_{f, t}-c_{f} \cdot d_{f, t}
$$

where $p_{f, t}$ and $d_{f, t}$ are, respectively, the price and the demand of firm $f$ 's product in period $t$, and $c_{f}$ is the constant unit cost of production of firm $i$, defined as 1.0 for all firms. There are no stocks and all products are sold or leave the market in each time period. For now, this is sufficient as the analysis is focusing on the process of product selection, innovation, and market dynamics. Thus, no differentiation of cost or inventory decisions was required.

\section{Model results}

It is proposed a total of five simulations. In section 6.1 there are presented three simulations with variation on demand parameters $(\Delta$ e $\tau)$. The first one considers initial settings $(\Delta=1) \tau=1$. At the second one it is established parameter $\Delta=0$ with the same value for $\tau$. At the third one the parameters are flexibilized for values $\Delta=0.05$ and $\tau=0.90$. All simulations in sections 6.1 included the two demand groups.

In section 6.2 the focus is on consumer preferences. Now the total amount of consumers is more sensitive to price - model 4 - or technological attribute - model 5 . Here the demand parameters are established equal to model 3. It follows the analysis. 


\subsection{Analysis of parameters of demand $(\Delta \mathrm{e} \tau)$}

The results discussed in this section are based on the parameter values in the previous section, and are shown in Table $1 .^{14}$

Table 1 - Initial parameters

\begin{tabular}{lr}
\hline Supply & 10 \\
\hline Firms & 1 \\
\hline Products by firm & 0.05 \\
\hline$y_{i}^{2}$ (technological dimension) & 1 \\
\hline$\alpha_{i, j}$ & 1 \\
\hline Global maximum & 1 \\
\hline$\Delta_{\mathrm{T}}$ & 1 \\
\hline$c_{i}$ (unit cost) & 100 \\
\hline Demand & 100 \\
\hline Group 1- price-dominant & 15 \\
\hline Group 2 - technology-dominant & 0 \\
\hline$m^{1}-$ maximum price & 1 \\
\hline$m^{2}-$ minimum technology & 1 \\
\hline$\Delta$ & \\
\hline$\tau$ & 0.01 \\
\hline Price & 0.02 \\
\hline$\alpha$ (market share variation) & 4 \\
\hline$s c$ (price variation) & \\
\hline$p_{f, t=0}$ (initial price) &
\end{tabular}

Source: Own elaboration.

Before present simulations results for market share it is presented the results for innovation made by firms in all simulation in the Figure 2. In a simulation with 300 periods, six radical innovations are made by four firms and nine incremental innovations are made by other firms ${ }^{15}$ (Fig. 3). These innovations are the same for all simulations below. It is important highlight that during the simulation period there is no technological lock-in for any firm since it is not achieved the global maximum (MAX $=1)$.

${ }^{14}$ It will be presented results for 300 periods. Simulations were tested for diferent random seeds, but we present results for the same random seed to make comparisons clear. Simulations were done in Laboratory of Simulation Development (LSD).

${ }^{15}$ Radical innovation is defined as a new product for the market. Incremental innovation is defined as a new product for the firm. 


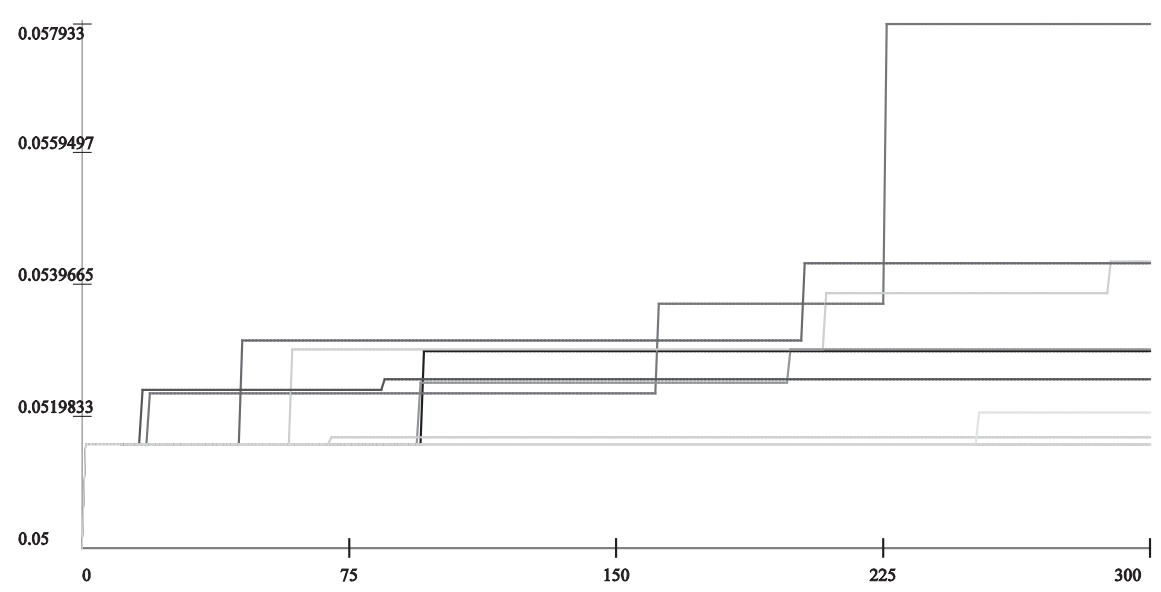

Fig. 2 - Innovations made by firms in simulations 1-5

Key: Firm 1, Firm 2, Firm 3, Firm 4, Firm 5, Firm 6, Firm 7, Firm 8, Firm 9, Firm 10

Source: Own elaboration.

In the first simulation, the market behavior follows a more competitive pattern, with an average market share of approximately $10 \%$ for firms. This result is as expected, as the consumer cannot identify product differentiations, and thus the innovations play no relevant role. Consumers have absolute perception errors $(\Delta=1)$ and maximum tolerance when comparing attributes $(\tau=1)$. Even if a firm develops an innovation, increasing the value of the technological feature $\left(y_{p}^{2}\right)$, the consumer can not identify this value $\left(v_{k}^{2}\right)$.

The results show the relevance of the information provided in the market when introducing an innovation. In the first simulation, the innovations are not sufficient for the innovative firm to derive market gains simply because the consumers do not recognize the superiority of their products (Fig. 3).

The radical innovations differ from the incremental ones once they have larger price and market share changes. All firms follow the same model of innovation, but some of them are able to innovate and change the market share and the price level, and affect the performance of other firms. This impact comes from the identification of such innovation by consumers, which then reallocates spending and choices. So, classifying an innovation as radical or incremental can only be done ex post, after assessing their impact on the market. 


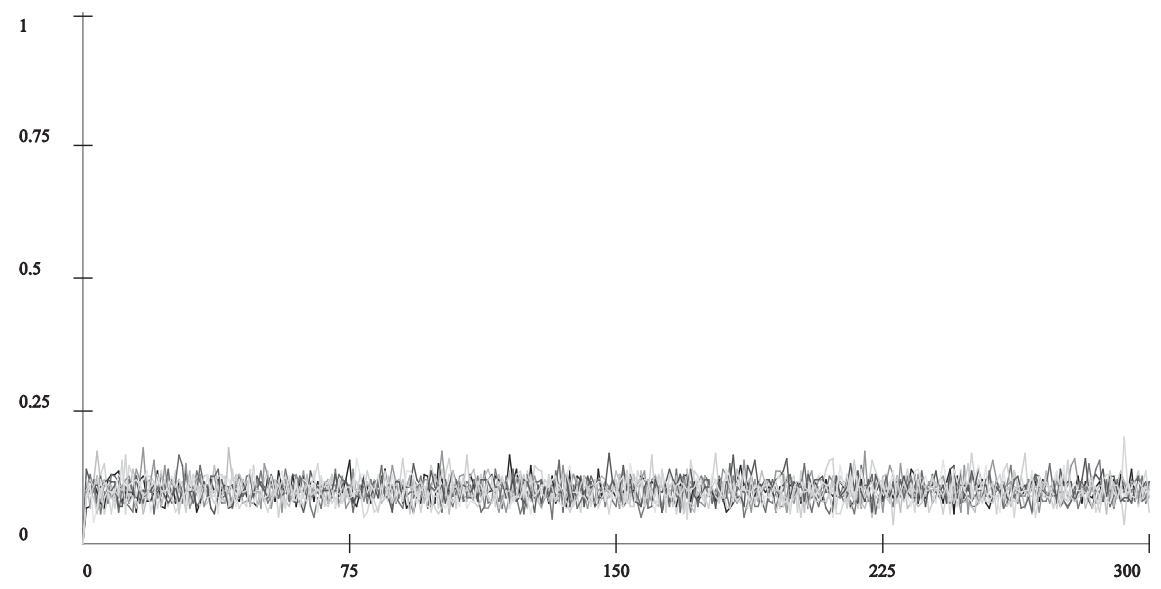

Fig. 3 - Simulation 1 - market share (initial settings: $\Delta=1 ; \tau=1$ )

Key: Firm 1, Firm 2, Firm 3, Firm 4, Firm 5, Firm 6, Firm 7, Firm 8, Firm 9, Firm 10

Source: Own elaboration.

The firm price is shown in Fig. 4. As consumers do not have perfect information about the characteristics of products, competition does not necessarily equalize the price and costs of production, nor it possible to have some relation with technological innovation. Firms do not necessarily compete on price because consumers do not distinguish different levels of price, since they are myopic regarding information and perfectly tolerant for this feature (besides technology). The result derived is a totally random choice made by consumers, where each firm has the same odds to sell its product.

It is worth to note that a competitive pattern still could be generated if it is allowed a better information and low tolerance regarding prices, keeping the same setting for technological features. At this case, the behavior of prices would be more intuitive, compatible with traditional pattern in perfect competition (prices reaching marginal cost and no profit). 


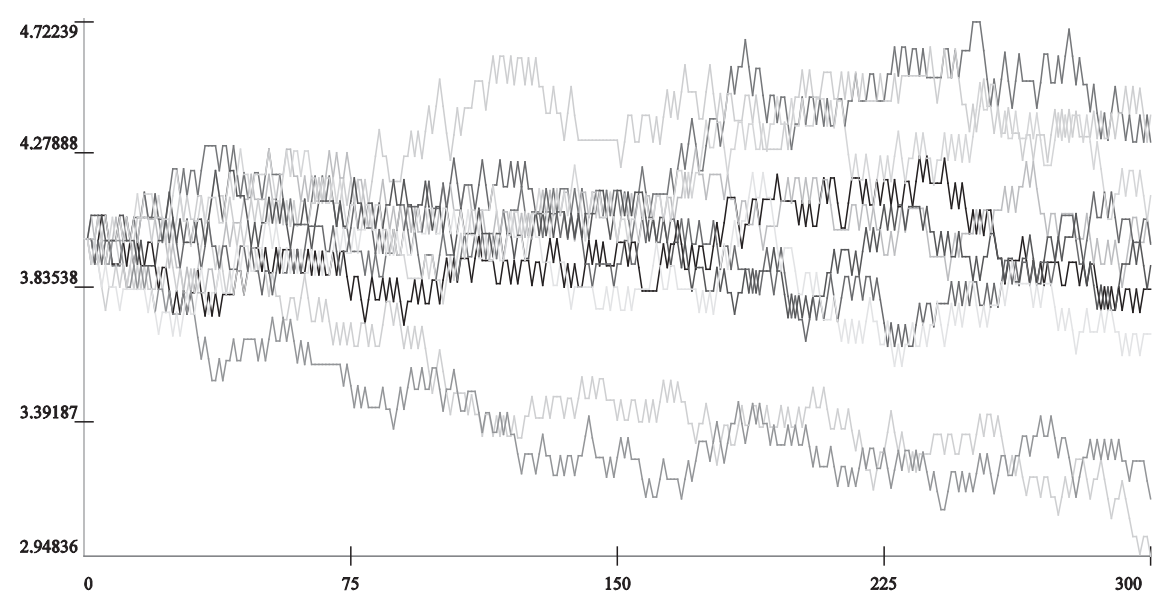

Fig. 4 - Simulation 1 - price charged by firms $(\Delta=1 ; \tau=1)$

Key: Firm 1, Firm 2, Firm 3, Firm 4, Firm 5, Firm 6, Firm 7, Firm 8, Firm 9, Firm 10

Source: Own elaboration.

The competitive result is not observed when the value of $\Delta$ is modified to $\Delta=0$ (Fig. 5). Now, consumers are fully tolerant, but they have perfect information about the economic and technical characteristics of all products offered.

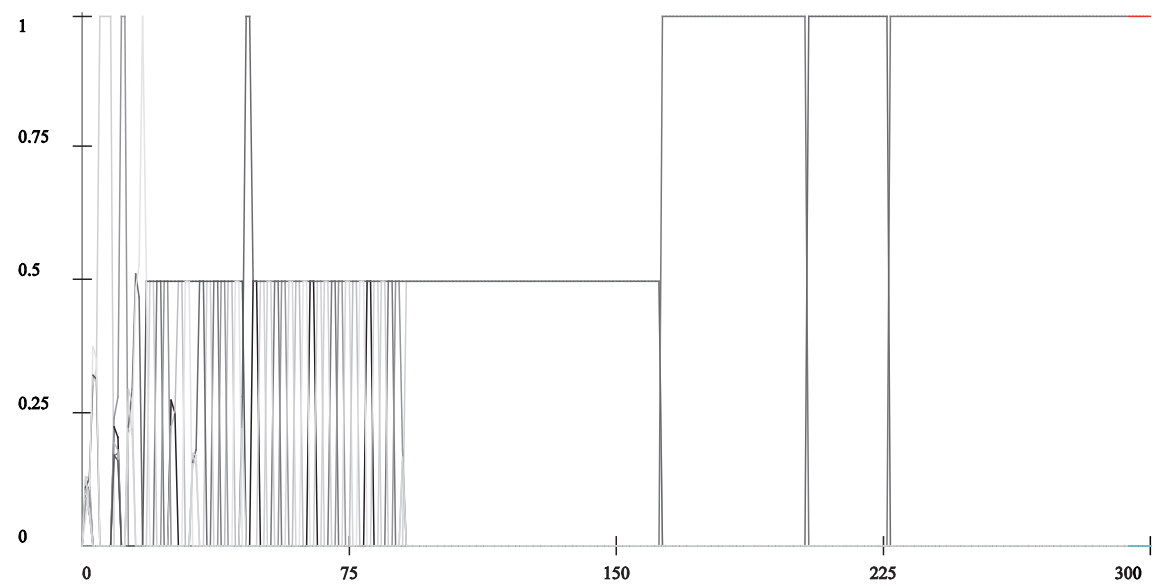

Fig. 5 - Simulation 2 - market share $(\Delta=0$ e $\tau=1)$

Key: Firm 1, Firm 2, Firm 3, Firm 4, Firm 5, Firm 6, Firm 7, Firm 8, Firm 9, Firm 10

Source: Own elaboration. 
When there are no perception errors, consumers can correctly access all the product features $\left(y_{k}^{X}=v_{k}^{X}\right)$ and have a perfect ordering of preferences. Among the innovations made by firms up to period 80, there is radical innovation that can distinguish one firm as superior to the others, so that firms engage in competition for market dominance through price setting, as shown in Fig. 6.

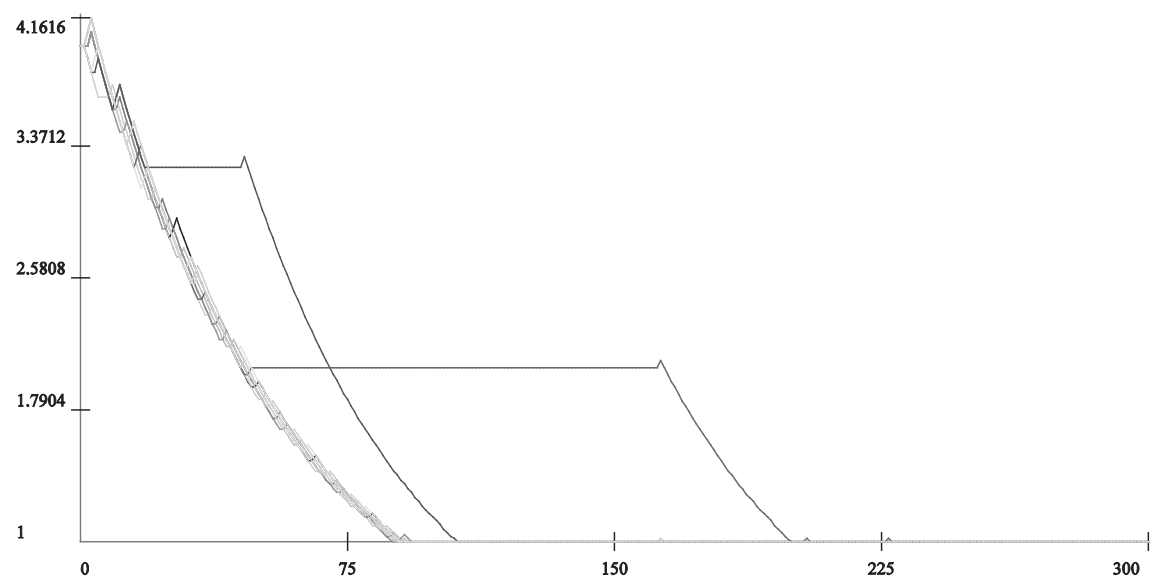

Fig. 6 - Simulation 2 - price charged by firms $(\Delta=0$ e $\tau=1)$

Key: Firm 1, Firm 2, Firm 3, Firm 4, Firm 5, Firm 6, Firm 7, Firm 8, Firm 9, Firm 10

Source: Own elaboration.

After period 80, the innovations carried out by two firms -4 and 6 - sustain the same differentiation of their products, giving them an advantage in market share for an extended period of time, as shown in Fig. 5. In Fig. 5, these two firms have 50\% of the market share between periods 80 and 160, losing their market shares only when firm 2 introduces another radical innovation and makes itself the new market leader, now with full leadership in a temporary monopoly setup.

This temporary monopoly is achieved by firm 2 when it creates a new product with a significant difference in quality compared to other competitors. Until this point, the innovations made by the firms have not fully been recognized by consumers as salient in differentiating them from other innovations due to the consumers' tolerance level in the analysis of product characteristics. Given the 
tolerance of consumers to prices and technological features, some products are classified as perfect substitutes.

However, when firm 2 introduces a radical innovation, consumers recognize this change in the technological parameter and mark it as denoting a superior product, and thus the temporary monopoly emerges. This result changes only when firm 6 innovates again, around period 200, completely taking up the market. This result is achieved because this new innovation by firm 6 also differentiates its product in relation to others. Finally, firm 2 achieves another temporary monopolistic situation.

After period 80, several firms set their prices to the minimum level and only those firms with products exhibiting features of a high technological level supply the market. Companies that have not made any changes to the technological features of their products or have made only incremental innovations cannot keep their products on the market. The analysis shows that the price charged by all fir$\mathrm{ms}$ is equal to the marginal cost of production as consumers always prefer radically innovative products, which drives their price to the minimum level.

This is the opposite result to the market competition shown in Fig. 2. In simulation 2 , there is an oligopoly with a high level of concentration or even a monopoly if the consumer has zero tolerance for technological and price differentials and there are no errors. In a world with informational symmetry for consumers and asymmetric innovative efforts by firms, a highly concentrated market would be quite usual in the presence of symmetric prices.

The simulations presented above can be considered special cases: highly concentrated or highly competitive, total tolerance to no tolerance, etc. Intermediate values for the main parameters would represent consumers with some tolerance to products with similar characteristics $(\tau \neq 1)$, and some misperceptions concerning these characteristics $(\Delta \neq 0)$. The simulation shown in Fig. 7 incorporates consumers with tolerance for product differentiation and errors in perception. Even for a small error in assessing product information, there is an oligopolistic and unstable dynamic in which the radical innovation plays its role in changing price and market share. 


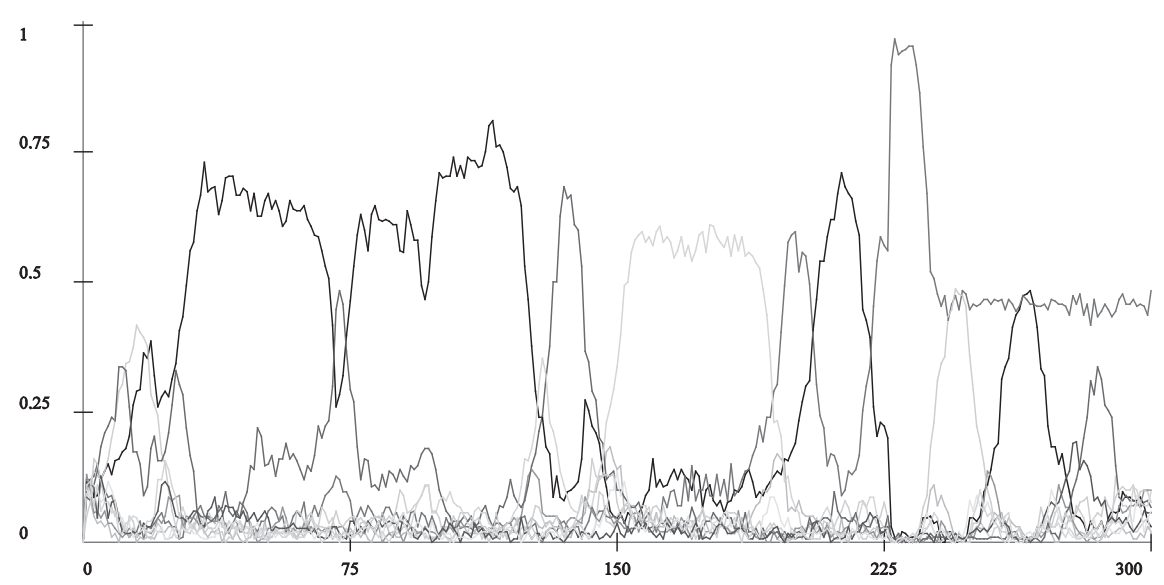

Fig. 7 - Simulation 3 - market share $(\Delta=0.05$ e $\tau=0,90)$

Key: Firm 1, Firm 2, Firm 3, Firm 4, Firm 5, Firm 6, Firm 7, Firm 8, Firm 9, Firm 10

Source: Own elaboration.

The impact of innovations in simulation 3 is lower than that in simulation 2 (Fig. 5). The innovation of firm 6 between periods 40 and 160 does not mean a large improvement in its market share because the radical innovation fails to produce a product with technological characteristics far superior to the others. The errors in perception and tolerance to different characteristics are sufficiently high for consumers to keep buying other products. Firm 1 sustains its leadership by keeping the most competitive prices (Fig. 8).

Only the radical innovation introduced by firm 2 at the end of the simulation shows a similar performance in market share. In this case, the value of the technological feature has been greatly improved, and is sufficient to give market leadership to firm 2. However, the misperceptions of consumers and tolerance for different products do not allow the innovative firm to obtain the entire market share; the other firms continue to sell their products with significant market shares after these radical innovations. 


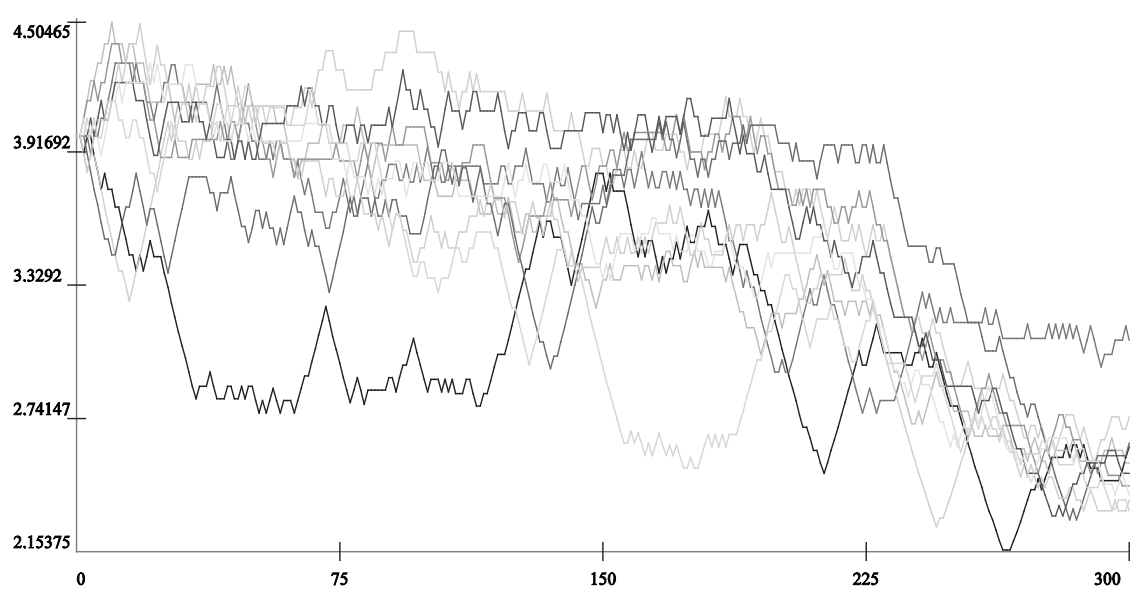

Fig. 8 - Simulation 3 - prices $(\Delta=0.05 e \tau=0,90)$

Key: Firm 1, Firm 2, Firm 3, Firm 4, Firm 5, Firm 6, Firm 7, Firm 8, Firm 9, Firm 10

Source: Own elaboration.

Perception errors and tolerance by consumers decrease the probability of firms increasing their market share very fast or to high levels. It is true, however, that these parameters should not be considered constant. Radical innovation increases the market share, especially in cases in which the products have few characteristics, some of which are dominant. Consumers learn about the products, thus reducing perception error in assessing attributes, and loyalty-in the case of acceptance of the product purchased-decreases tolerance in the comparison of supply. The simulation shows the importance of sales force training and marketing strategies. In the popular jargon, "it is not enough to do better; you must show that it is better." Valente (2012) presents an analysis in relation to these issues. In addition, the "error correction" of consumers also occurs with firms that mimic the success of their competitors through product imitation. 


\subsection{Analysis of consumer preferences}

So far, the simulations have included one set of consumers. However, with two different types of consumer, the simulations may change. For example, there is an even number of consumers with a preference related to price and other consumers with a preference related to quality or technological attributes. Let us set 100 consumers for each type of consumer.

The simulations with two types of consumer are shown below. To proceed with this analysis, we define values $\Delta$ and $\tau$ as used in the simulation of Fig. $7(\Delta=0.05 ; \tau=0.90)$. Suppose initially that there are only consumers in group 1, who order their first purchases based on the price of the products offered. This assumption means that now group 1 has 200 consumers and group 2 has no consumers. This analysis is presented in Fig. 9.

In this case, the market dynamics in relation to innovative firms tends to be more competitive because consumers are more likely to consider the price, and thus innovation is not as important as in the previous simulation. The market shows less volatility to innovations and is closer to the competitive industry pattern. When the firms introduce an innovation, the market share is lower than in the previous case because the innovative firm increases its price and cuts short the increase in the market share. However, when all consumers have a strong preference for innovation (only consumers in group 2) and none of them see price as an important determinant of purchase, the market has a different time path as Fig. 10 shows. 


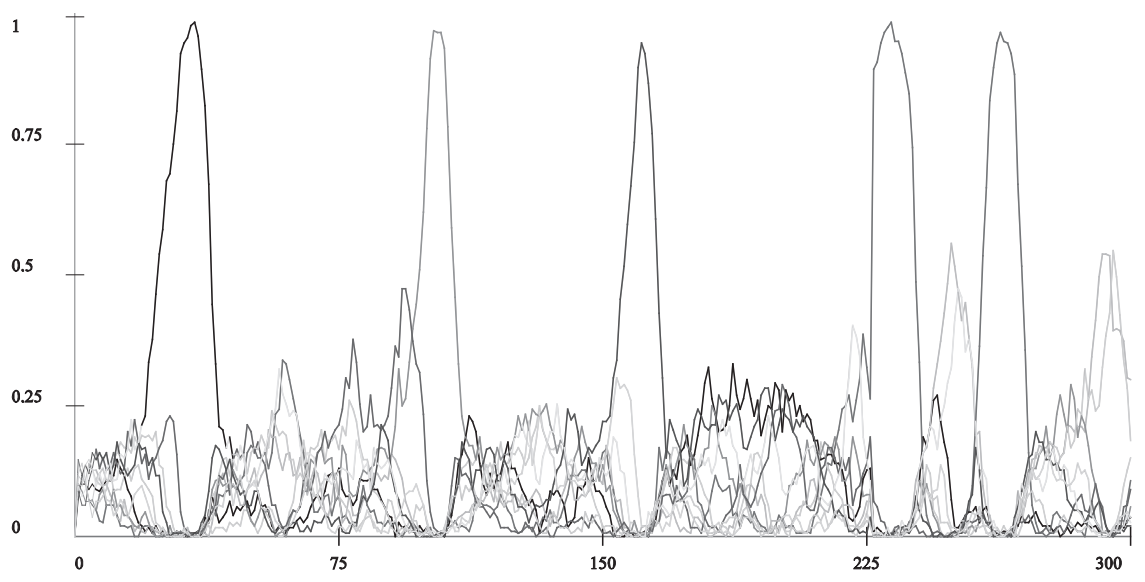

Fig. 9 - Simulation 4 - market share (consumer group 1: $\Delta=0.05 e \tau=0,90$ )

Key: Firm 1, Firm 2, Firm 3, Firm 4, Firm 5, Firm 6, Firm 7, Firm 8, Firm 9, Firm 10

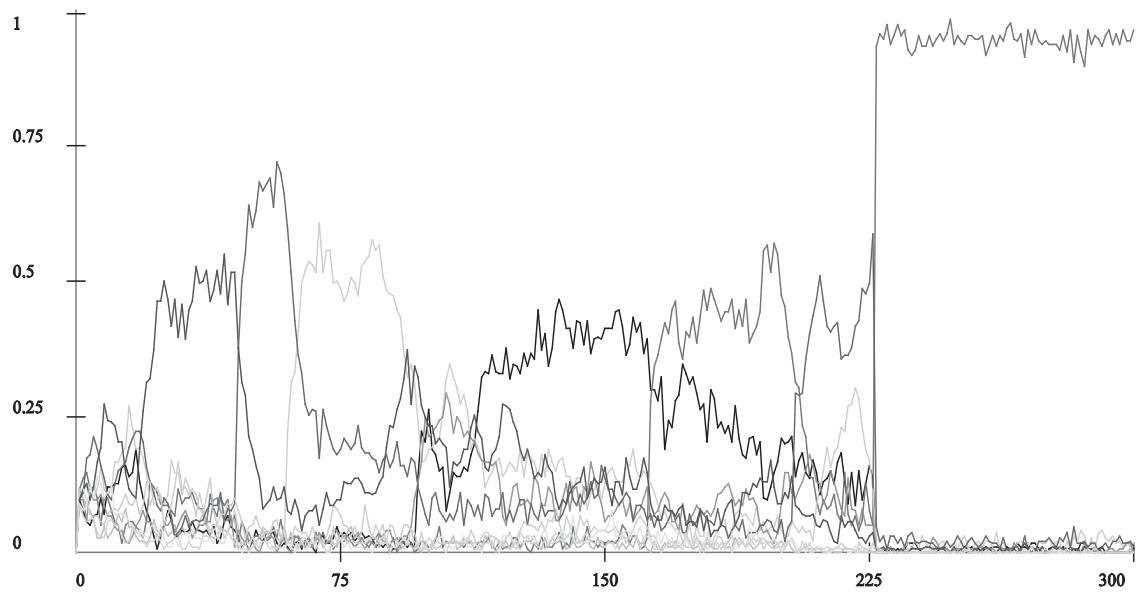

Fig. 10 - Simulation 5 - market share (consumer group 2: $\Delta=0.05$ e $\tau=0,90$ )

Key: Firm 1, Firm 2, Firm 3, Firm 4, Firm 5, Firm 6, Firm 7, Firm 8, Firm 9, Firm 10

Source: Own elaboration.

In simulation 5, the perception of market innovation is higher in terms of consumers' preference for basing their choice on technological attributes. Even if the prices of products show large variation driven by changes in market share, consumers hold to their preference for 
new products of better quality. Radical innovations made by firms 2,4 , and 6 during the simulation generate higher market share for these firms.

These comparisons clearly show the importance of considering the preference for technological attributes and/or quality over price, especially in an oligopolistic market analysis. A firm that leads consumers to choose based on these technological attributes ensures greater relevance in terms of market share even when prices increase. In marketing jargon, "it is not enough to do better; you must do what the buyer likes best."

\subsection{Comparative results}

Table 2 summarizes the simulations. The table presents information on the Hirschman-Herfindahl index of industrial concentration, average market share, average price, and average profit for "Firms with radical innovations" and "Other firms" (no radical innovation). As noted in Fig. 3, those firms with radical innovations are 2, 6, 8, and 10 .

Among the simulations, there are two traditional outcomes: the competitive market case and the monopolistic case, even though there is no natural monopoly. When consumers can identify/classify product differentiation by innovative firms, the market contains firms with a high degree of market power, a result corroborated by the analysis of the average market share of firms with radical innovations.

The results for "Firms with radical innovations" and "Other firms" are quite different for the simulations. As can be observed, when consumers have better information about product features, or when they have revealed a preference for technological features, the results for radically innovative firms in terms of price and profit tend to be better vis-à-vis the results for simulation 1 .

However, this result is not valid for simulation 2 (Fig. 5). Even in a monopoly structure, the price drops in the initial periods with competition; this leads to worse results for innovative firms in the simulation. This is a case in which the consumers' knowledge about 
product features establishes a competitive advantage in earlier periods, when there is little product differentiation. So, when innovation occurs, market prices and profitability are already at a low level compared to other simulations.

Table 2 - Summary of simulations

\begin{tabular}{|c|c|c|c|c|c|c|}
\hline \multirow[t]{2}{*}{ Simulation } & \multirow[t]{2}{*}{$\begin{array}{l}\text { Stylized } \\
\text { pattern }\end{array}$} & \multirow[t]{2}{*}{ Variables } & $\begin{array}{l}\text { Firms with } \\
\text { radical } \\
\text { innovations }\end{array}$ & $\begin{array}{l}\text { Other } \\
\text { firms }\end{array}$ & $\begin{array}{l}\text { Firms with } \\
\text { radical } \\
\text { innovations }\end{array}$ & $\begin{array}{l}\text { Other } \\
\text { firms }\end{array}$ \\
\hline & & & \multicolumn{2}{|c|}{ Real values } & \multicolumn{2}{|c|}{$\%$ in relation to $\operatorname{Sim} 1$} \\
\hline \multirow{4}{*}{$\operatorname{Sim} 1$} & \multirow{4}{*}{$\begin{array}{l}\text { Perfect compe- } \\
\text { tition }\end{array}$} & Average $\mathrm{HH}$ & \multicolumn{2}{|c|}{0.105} & \multicolumn{2}{|l|}{ - } \\
\hline & & Average market share & 0.102 & 0.098 & - & - \\
\hline & & Average price & 3.82 & 4.01 & - & - \\
\hline & & Average profit & 57.50 & 59.29 & - & - \\
\hline \multirow{4}{*}{$\operatorname{Sim} 2$} & \multirow{4}{*}{ Monopoly } & Average $\mathrm{HH}$ & \multicolumn{2}{|c|}{0.737} & \multicolumn{2}{|c|}{$605 \%$} \\
\hline & & Average market share & 0.344 & 0.038 & $238 \%$ & $-61 \%$ \\
\hline & & Average price & 1.57 & 1.40 & $-59 \%$ & $-65 \%$ \\
\hline & & Average profit & 24.83 & 7.68 & $-57 \%$ & $-87 \%$ \\
\hline \multirow{4}{*}{$\operatorname{Sim} 3$} & \multirow{4}{*}{$\begin{array}{l}\text { Oligopoly } \\
\text { Two consumer } \\
\text { groups }\end{array}$} & Average $\mathrm{HH}$ & \multicolumn{2}{|c|}{0.372} & \multicolumn{2}{|c|}{$256 \%$} \\
\hline & & Average market share & 0.158 & 0.084 & $56 \%$ & $-14 \%$ \\
\hline & & Average price & 3.57 & 3.47 & $-6 \%$ & $-13 \%$ \\
\hline & & Average profit & 72.50 & 35.28 & $26 \%$ & $-40 \%$ \\
\hline \multirow{4}{*}{$\operatorname{Sim} 4$} & \multirow{4}{*}{$\begin{array}{l}\text { Oligopoly } \\
\text { Consumers } \\
\text { prefer price }\end{array}$} & Average $\mathrm{HH}$ & \multicolumn{2}{|c|}{0.286} & \multicolumn{2}{|c|}{$173 \%$} \\
\hline & & Average market share & 0.109 & 0.097 & $7 \%$ & $-1 \%$ \\
\hline & & Average price & 2.95 & 2.62 & $-23 \%$ & $-35 \%$ \\
\hline & & Average profit & 36.78 & 33.25 & $-36 \%$ & $-44 \%$ \\
\hline \multirow{4}{*}{ Sim 5} & \multirow{4}{*}{$\begin{array}{l}\text { Oligopoly } \\
\text { Consumers } \\
\text { prefer technol- } \\
\text { ogy }\end{array}$} & Average $\mathrm{HH}$ & \multicolumn{2}{|c|}{0.422} & \multicolumn{2}{|c|}{$304 \%$} \\
\hline & & Average market share & 0.230 & 0.067 & $127 \%$ & $-32 \%$ \\
\hline & & Average price & 4.25 & 3.35 & $11 \%$ & $-16 \%$ \\
\hline & & Average profit & 145.08 & 36.50 & $152 \%$ & $-38 \%$ \\
\hline
\end{tabular}

Source: Own elaboration.

\section{Conclusions}

This article has discussed product innovation in a model in which consumers have asymmetric information and different preferences, choosing products following a simple procedure (take-the-best choice). Firms innovate, searching for new products without being in possession of full knowledge of the consumer choices. The model is based on the contributions of Valente $(2012,2014)$. 
The simulations show the importance of information and the process of choosing in shaping demand and the performance of products in the market place. It can be observed that the inability of consumers to access and process market information on product quality correctly as a result of high transaction costs affects market outcomes. High market concentration related to product innovation is achieved only when there is no perception error and no consumer tolerance for products; consumers have complete information on price and technological caracteristics and simply buy the best choice on the market. Thus, the model shows the importance of the process underpinning consumer choice and the role of information in an industry in which product innovation plays a significant role.

In summary, it is important for firms to inform consumers of the different attributes of their products to ensure the success of innovation. Innovation is more than developing new technological characteristics; it also involves strategies related to information, marketing, and the control of distribution channels, so that performance can be demonstrated and be recognized by consumers. A successful innovation is not "just a better good; it needs to show that it is better." Furthermore, differentiating between consumers accords them importance in the process of innovation. Firms that introduce new products to the market have to realize that "it is not enough to do better; it has to make the buyer like the best."

The results observed here are preliminary. There are several simplifications and the model can be improved to allow a deeper understanding of innovation and choice. However, the work thus far shows that the heterogeneity of demand is important, especially when dealing with industries with complex technologies, heterogeneous products, asymmetric and not fully available information, non-transparent pricing strategies, and heterogeneity in consumers. 


\section{Bibliography}

AKERLOF, G. A., "The Market for 'Lemons': Quality Uncertainty and the Market Mechanism.” Quarterly Journal of Economics, 84(3), pp. 488-500, 1970.

AVERSI, R., DOSI, G., FAGIOLO, G., MEACCI, M., OLIVETTI, C.Demand Dynamics With Socially Evolving Preferences. Industrial and Corporate Change, 8(2), 353-408, 1999.

CAVES, R. E. \& PORTER, M. E. "From Entry Barriers to Mobility Barriers: Conjectural Decisions and Contrived Deterrence to New Competition”. The Quarterly Journal of Economics, Vol. 91, No. 2. (May, 1977), pp. 241-262, 1977.

GIGERENZER, G. Adaptive thinking: Rationality in the real world, Oxford Universtiy Press.

GIGERENZER, G. \& GOLDSTEIN, D. (1996), "Reasoning the Fast and Frugal Way: Models of Bounded Rationality", Psychological Review, 103(4), pp. 650-69, 2000.

GIGERENZER, G., SELTEN, R., eds. Bounded rationality: The adaptive toolbox, MIT Press, 2000.

KAUFFMAN, S. A. The Origins of Order: Self-Organization and Selection in Evolution, Oxford University Press, 1993.

LUNDVALL, B. Innovation as an interactive process: from user-producer interaction to the national system of innovation. In: DOSI, G et al. (eds) Technical change and economic theory. Pinter, London, 1988.

MALERBA, F., NELSON, R., ORSENIGO, L., WINTER, S. Demand, innovation, and the dynamics of market structure: The role of experimental users and diverse preferences. Journal of Evolutionary Economics, 17, 371-399, 2007.

METCALFE, J. S. Consumption, preferences, and the evolutionary agenda. Journal of Evolutionary Economics, 11(1), pp. 37-58, 2001.

NELSON, P. Information and Consumer Behaviour, Journal of Political Economy, 78(2), pp. 311-329, 1970.

NELSON, P. Advertising as Information. The journal of political economy, 82.4, 729-754, 1974.

NELSON, R. Demand, supply, and their interaction on markets, as seen from the perspective of evolutionary economic theory. Journal of Evolutionary Economics, 23, 17-38, 2013.

NELSON, R., CONSOLI, D. “An evolutionary theory of household consumption behavior”, Journal of Evolutionary Economics, 20(5), pp. 665-87, 2010.

OLSHAVSKY, R. W., GRANBOIS, D. H. Consumer Decision Making - Fact or Fiction? Journal of Consumer Research, 6, 93-100, 1979.

PORTER, M. E. "How competitive forces shape strategy”, Harvard business Review, March/April, 1979.

PORTER, M. E. Competitive Strategy, Free Press, New York, 1980.

SAVIOTTI, P. P. Variety, Growth and Demand. Journal of Evolutionary Economics, 11(1), pp. 119$142,2001$.

SIMON, H. A. A Behavioral Model of Rational Choice. The Quarterly Journal of Economics, v.69, n.1, (feb.1955), pp. 99-118, 1955.

SIMON, H. A. From Substantive to Procedural Rationality. In.: LATSIS, S. J. (ed.), Method and Appraisal in Economics, Cambridge: Cambridge University Press, pp. 129-148, 1976.

SIMON, H. A. Rationality as process and as product of thought. American Economic Review, 68(2), pp. 1-16, 1978.

SIMON, H. A. Rational Decision Making in Business Organizations. [Nobel Memorial Lecture], American Economic Review, 69(4), September, pp. 493-513, 1979.

SLOVIC, P. Choice. In.: Osherson, D. N., Smith, E. E. (eds) An Invitation to Cognitive Science. MIT Press: Cambridge, MA, 1990.

Estud. Econ., São Paulo, vol.47, n.1, p.5-37, jan.-mar. 2017 
STIGLER, G. The economics of information, Journal of Political Economy, 69(3): 213-25, 1961.

THALER, R. H. The Winner's Curse: Paradoxes and Anomalies of Economics Life. Free Press: New York, 1992.

TVERSKY, A., KAHNEMAN, D. Rational Choice and the Framing of Decisions. Journal of Business, 59, 251-278, 1986.

VALENTE, M. Evolutionary Demand: a Model for Boundedly Rational Consumers. Journal of Evolutionary Economics. 22, 1029-1080, 2012.

VALENTE, M. An NK-like Model for Complexity. Journal of Evolutionary Economics. 24, 107-134, 2014.

WILLIAMSON, O. E. "Transaction Cost Economics", in Handbook of Industrial Organization, Volume I, Edited by R. Schmalensee and R.D. Willing, Elsevier Science Publishers, 1989.

WINDRUM, P., BIRCHENHALL, C. Is product life cycle theory a special case? Dominant designs and the emergence of market niches through coevolutionary-learning. Structural Change and Economic Dynamics, 9, 109-134, 1998.

WINDRUM, P., CIARLI, T., BIRCHENHALL, C. Consumer heterogeneity and the development of environmentally friendly technologies, Technological Forecasting and Social Change, 76(4), pp. 533-51, 2009. 